\title{
Automated haematology analysis to diagnose malaria
}

\author{
Germán Campuzano-Zuluaga ${ }^{1,2}$, Thomas Hänscheid ${ }^{3}$, Martin P Grobusch ${ }^{4,5,6^{*}}$
}

\begin{abstract}
For more than a decade, flow cytometry-based automated haematology analysers have been studied for malaria diagnosis. Although current haematology analysers are not specifically designed to detect malaria-related abnormalities, most studies have found sensitivities that comply with WHO malaria-diagnostic guidelines, i.e. $\geq 95 \%$ in samples with $>100$ parasites/ $\mu$ l. Establishing a correct and early malaria diagnosis is a prerequisite for an adequate treatment and to minimizing adverse outcomes. Expert light microscopy remains the 'gold standard' for malaria diagnosis in most clinical settings. However, it requires an explicit request from clinicians and has variable accuracy. Malaria diagnosis with flow cytometry-based haematology analysers could become an important adjuvant diagnostic tool in the routine laboratory work-up of febrile patients in or returning from malaria-endemic regions. Haematology analysers so far studied for malaria diagnosis are the Cell-Dyn ${ }^{\circledR}$, Coulter ${ }^{\circledR} \mathrm{GEN} \cdot S$ and LH 750, and the Sysmex XE- $2100^{\circledR}$ analysers. For Cell-Dyn analysers, abnormal depolarization events mainly in the lobularity/granularity and other scatter-plots, and various reticulocyte abnormalities have shown overall sensitivities and specificities of $49 \%$ to $97 \%$ and $61 \%$ to $100 \%$, respectively. For the Coulter analysers, a 'malaria factor' using the monocyte and lymphocyte size standard deviations obtained by impedance detection has shown overall sensitivities and specificities of $82 \%$ to $98 \%$ and $72 \%$ to $94 \%$, respectively. For the XE-2100, abnormal patterns in the DIFF, WBC/BASO, and RETEXT scatter-plots, and pseudoeosinophilia and other abnormal haematological variables have been described, and multivariate diagnostic models have been designed with overall sensitivities and specificities of $86 \%$ to $97 \%$ and $81 \%$ to $98 \%$, respectively. The accuracy for malaria diagnosis may vary according to species, parasite load, immunity and clinical context where the method is applied. Future developments in new haematology analysers such as considerably simplified, robust and inexpensive devices for malaria detection fitted with an automatically generated alert could improve the detection capacity of these instruments and potentially expand their clinical utility in malaria diagnosis.
\end{abstract}

\section{Malaria diagnostic methods - 'where to use what'} For over a century microscopy has been the standard method for routine malaria diagnosis [1], allowing species identification and determination of parasitaemia, with a detection threshold of 4 to 100 parasites/ $\mu \mathrm{l}[2]$. Microscopy-based diagnosis is performed mostly in areas of low to moderate transmission, for example Latin-America, or parts of Asia and South Africa [3]. Interestingly, and despite the experience of microscopists, studies from endemic countries, such as India and South Africa, have shown that laboratory misdiagnosis is

\footnotetext{
* Correspondence: m.p.grobusch@amc.uva.n

${ }^{4}$ Infectious Diseases, Tropical Medicine and AIDS, Division of Internal Medicine, Academic Medical Centre, University of Amsterdam, Meibergdreef 9, PO Box 22660, 1100 DE Amsterdam, The Netherlands

Full list of author information is available at the end of the article
}

not uncommon $[4,5]$. This may be due to the immense workload and limited human resources. Laboratory misdiagnosis may also occur in developed countries with imported malaria [6], as laboratories in these areas deal with few cases annually, thus making it difficult to maintain the laboratory expertise in microscopic diagnosis. The need for well-trained microscopists, lack of equipment and/or periodic training, has led to the development of several alternative diagnostic methods [7]. Also, immunochromatographic rapid diagnostic tests (RDTs) have become widespread. In resource-poor areas, usually those with high malaria transmission rates, expensive artemisinin-based combination therapies are increasingly used, and this has led to the promotion of RDTs by malaria control programmes, as stipulated

\section{() Biomed Central}


by WHO [8], as a prerequisite to 'informed' therapy with artemisinin combination therapy (ACT) [9].

Early parasitological malaria diagnosis is required to guide proper treatment and reduce adverse outcomes associated with the infection [10]. Lack of clinical and laboratory experience, prolonged incubation periods and Plasmodium vivax relapses $[11,12]$, or prophylaxis in travellers [13] can delay diagnosis, thus increasing malaria associated adverse outcomes [14], especially in non-endemic countries. In a Canadian study, in patients with imported malaria, $45 \%$ infected with $P$. vivax, 33\% with Plasmodium falciparum, $22 \%$ with other species or mixed malaria, $59 \%$ cases were missed on first presentation and $16 \%$ had $\geq 3$ physician-contacts before malaria smears were ordered [15]. A study evaluating 185 malaria-related fatalities in travellers returning to the United States, of which $92.7 \%$ were caused by $P$. falciparum, $3.3 \%$ by $P$. vivax and the remainder by other species, found that $67.8 \%$ of these patients were not diagnosed in the first visit, $17.9 \%$ were diagnosed at autopsy, and $66.7 \%$ of preventable deaths were attributed to management failure upon presentation [14]. A reliable detection method for malaria incorporated into the routine complete blood count $(\mathrm{CBC})$ could help detect cases earlier and potentially reduce adverse outcomes related to malaria infection.

\section{Discovery of automated haematology analysers for malaria diagnosis}

The $\mathrm{CBC}$ is one of the most frequently requested laboratory tests in clinical medicine [16] with multiple indications, including the evaluation of febrile patients that could have malaria [17]. Furthermore, these instruments are available throughout the developed, and also increasingly so in the developing world. Most of these instruments are based on flow cytometry and have proven to be of value for malaria diagnosis $[18,19]$. Back in 1953, the first haematology analyser developed by Wallace Coulter was based solely on impedance detection (Coulter Principle) [16,20]. These instruments have evolved quickly and have incorporated chemical methods, direct current impedance, radiofrequency conductance, flow cytometry multiple-angle light scatter, and nucleic acid fluorescence detection methods for characterization of the blood cell populations, and provide highly accurate CBCs $[21,22]$. For those interested in the basic mechanisms by which haematology analysers measure and characterize blood corpuscles we refer the reader to several good reviews [21,23].

Until the early 1990s, anecdotal cases of malaria-related alterations in the $\mathrm{CBC}$ were described; for example, abnormal extra peaks in the white blood cell (WBC) histograms of a Coulter ${ }^{\circledR}$ MaxM analyser (Beckman-Coulter, Inc, Miami, FL, USA) (Germán Campuzano-Maya, personal communication) and pseudoreticulocytosis in a Sysmex R-1000 (Sysmex Corporation, Kobe, Japan) [24]. In 1993, a study analysing 18 samples from patients with malaria (P. falciparum: 10 and P. vivax: 8 ) and 52 samples from healthy controls with a Technicon $\mathrm{H}^{\oplus}$ analyser (Technicon Instruments Corporation, Tarry Town, NY; now Siemens), found that all malaria-infected patients had $\geq 3 \%$ (range 3.3-20.9\%) of so-called 'large-unstainedcells' suggesting their potential use for malaria screening [25]. Unfortunately, changes in WBC populations [26], reticulocytosis, or increase of 'large-unstained-cells' [25] may also appear with other pathologies, giving these changes low accuracy for malaria detection.

The interest in haematology analysers was renewed after a first report showing that a Cell-Dyn ${ }^{\oplus}(C D)$ analyser (Abbott Diagnostics, Santa Clara, CA, USA) allowed for a rather specific detection of malaria pigment in leukocytes [18]. This discovery led to a series of studies (Table 1 and Additional File 1), which have confirmed the potential of these instruments to aid in the diagnosis of malaria. In more recent years, other researchers have set out to investigate if other haematology analysers could also detect malaria, focusing on the Coulter ${ }^{\circledR}$ GEN.S and LH 750 (Beckman Coulter, Inc, Miami, FL, USA), and the Sysmex XE-2100 ${ }^{\oplus}$ (Sysmex Corporation, Kobe, Japan). This review describes relevant key features of these analysers, characteristic malaria-related findings, diagnostic accuracy, clinical applications and limitations, as well as future directions of this novel malaria diagnosis modality.

\section{Cell-Dyn analysers and detection of malaria pigment (haemozoin)}

The Cell-Dyn instruments use laser light scatter at various angles, the so called multiple-angle polarized scatter separation for WBC analysis. Multiple-angle polarized scatter separation is used to distinguish eosinophils from neutrophils based on the light depolarizing properties of their granules, but has also been found to detect haemozoin-containing monocytes and granulocytes (Figures 1 and 2) [18,27-29]. These malaria-related events are shown in a scatter-plot with $90^{\circ}$ side-scatter on the $x$-axis and $90^{\circ}$ depolarized side-scatter on the $y$-axis, usually labelled as lobularity/granularity scatter-plot in the CD 3000 series or NEU-EOS in the CD 4000 (Figures 1 and 2).

Using a $\mathrm{MoFlo}^{\oplus}$ high speed cell sorter (Beckman Coulter, Inc, Fullerton, CA), it was confirmed that the observed changes were caused by haemozoin-containing monocytes and neutrophils [27,29], as did a study where samples from monocytes, which had previously ingested haemozoin in-vitro, produced depolarizing events in the side-scatter/ depolarized side-scatter plot of a CD 3200 [30]. Interestingly, there is evidence that depolarizing material in intraerythrocytic parasites could also be detected $[31,32]$. 
Table 1 Summary of studies evaluating the malaria diagnostic accuracy of Cell-Dyn series analysers using the side-scatter/depolarized side-scatter plot abnormal depolarizing events criterion. $\$$

\begin{tabular}{|c|c|c|c|c|}
\hline $\begin{array}{l}\text { First author, year and } \\
\text { country }\end{array}$ & Number of participants and diagnoses & Index test criterion" & $\begin{array}{l}\text { Sensitivity } \\
\%\end{array}$ & $\begin{array}{l}\text { Specificity } \\
\%\end{array}$ \\
\hline $\begin{array}{l}\text { Mendelow, 1999, South } \\
\text { Africa [18] }\end{array}$ & Total: 224 directed samples from 175 patients, P. falciparum: 93, Species not specified: 2 & $\begin{array}{l}C D^{* *} 3500 \\
\geq 1 \text { depolarizing events } \neq\end{array}$ & 72 & 96 \\
\hline $\begin{array}{l}\text { Hänscheid, 2001, } \\
\text { Portugalt [39] }\end{array}$ & Total: 174, P. falciparum: 48 , P. vivax: 6, P. ovale: 1, P. malariae: 2 & $\begin{array}{l}\text { CD } 3500 \\
\geq 2 \text { depolarizing events }\end{array}$ & 95 & 88 \\
\hline $\begin{array}{l}\text { Wever, 2002, The } \\
\text { Netherlandst [36] }\end{array}$ & Total: 113, P. falciparum: 46, P. vivax: 5, P. ovale: 4, no differentiation for $P$. vivax or $P$. ovale: 3 & $\begin{array}{l}\text { CD } 3500 \\
\text { Either } \geq 1 \text { depolarizing events or } \\
\text { pseudoreticulocytosis }\end{array}$ & 62 & 96 \\
\hline $\begin{array}{l}\text { Grobusch, 2003, } \\
\text { Germanyt [27] }\end{array}$ & Total: 403, P. falciparum: 87, P. vivax: 13 , P. ovale: 5, P. malariae: 2 & $\begin{array}{l}\text { CD } 3000 \\
\geq 1 \text { depolarizing events }\end{array}$ & 48.6 & 96.2 \\
\hline $\begin{array}{l}\text { Scott, 2003, South Africa } \\
\text { [35] }\end{array}$ & Total: 831, P. falciparum: 334, P. vivax: 7, P. ovale: 1, P. malariae: 2, mixed or unspecified: 6 & $\begin{array}{l}\text { CD } 4000 \\
\geq 1 \text { depolarizing events }\end{array}$ & 80.2 & 87.3 \\
\hline $\begin{array}{l}\text { Suh, 2003, South Korea } \\
\text { [32] }\end{array}$ & Total: 168, P. vivax: 68 & $\begin{array}{l}\text { CD } 4000 \\
\geq 1 \text { depolarizing events }\end{array}$ & 91.2 & 100 \\
\hline $\begin{array}{l}\text { Dromigny, 2005, Senegal } \\
\text { [30] }\end{array}$ & $\begin{array}{l}\text { Total: } 799 \text { (directed: suspected of malaria 123, non-suspected random samples 676) P. falciparum: } \\
68 \text {, treated or subclinical: } 83\end{array}$ & $\begin{array}{l}\text { CD } 3200 \\
\geq 1 \text { depolarizing events }\end{array}$ & $\begin{array}{c}\text { Directed } \\
92.9 \\
\text { Random } \\
90.2\end{array}$ & $\begin{array}{c}\text { Directed } \\
93.8 \\
\text { Random } \\
96.7\end{array}$ \\
\hline $\begin{array}{l}\text { Padial, 2005, Equatorial } \\
\text { Guinea [41] }\end{array}$ & Total: 411, P. falciparum: 35 , P. ovale: 3, mixed: 1 & CD 4000 & 72 & 98 \\
\hline $\begin{array}{l}\text { Josephine, 2005, } \\
\text { Malaysia [40] }\end{array}$ & Total: 889, P. vivax: 12, P. malariae: 3, P. falciparum: 1 & CD 4000 & 100 & 100 \\
\hline $\begin{array}{l}\text { de Langen, 2006, } \\
\text { Namibia [42] }\end{array}$ & Total: 208, P. falciparum: 90 & $\begin{array}{c}\text { CD } 3700 \\
\geq 1 \text { depolarizing events }\end{array}$ & 93 & 97 \\
\hline $\begin{array}{l}\text { Hänscheid, 2008, } \\
\text { Gabon [34] }\end{array}$ & Children, total: 368, P. falciparum: 152 & $\begin{array}{l}\text { CD } 3000^{* * *} \\
\geq 1 \text { depolarizing purple events Green- } \\
\text { coded events }\end{array}$ & $\begin{array}{l}\text { a) } 96 \% \\
\text { b) } 85 \%\end{array}$ & $\begin{array}{l}\text { a) } 96 \% \\
\text { b) } 96 \%\end{array}$ \\
\hline $\begin{array}{l}\text { Hänscheid, 2009, } \\
\text { Gabon [43] }\end{array}$ & Pregnant patients, total 685, P. falciparum: 86 & $\begin{array}{c}\text { CD } 3000 \\
\geq 1 \text { depolarizing events }\end{array}$ & 86.8 & 78.5 \\
\hline Rathod, 2009, India [33] & Total: 523, P. falciparum :73, P. vivax: 62 & $\begin{array}{c}\text { CD } 3200 \\
\geq 1 \text { depolarizing events }\end{array}$ & 62.2 & 25.3 \\
\hline
\end{tabular}

"Index diagnostic test: abnormal depolarizing events in the side-scatter/depolarized side-scatter plot. ¥All studies use the instrument's diagonal separation line for eosinophils and neutrophils in the side-scatter/ depolarized side-scatter plot, unless otherwise specified. ** CD: Cell-Dyn. +Imported malaria. ***For purple events, these were considered positive if present above a line traced at 5 pixels from the $x$ axis. For green events, a special gate was created to identify haemozoin-laden granulocytes, with the intention to exclude eosinophils. In accordance with studies using flow cytometric cell sorting [27], the largest possible gate to the left and above the usual location of the eosinophil population was created which did not contain any eosinophils [34]. For this, CBC analyses from children without malaria or pseudoreticulocytosis were used [34]. ${ }^{5}$ For the complete table with additional comments and reference diagnostic tests used in each study see Additional File 1. 


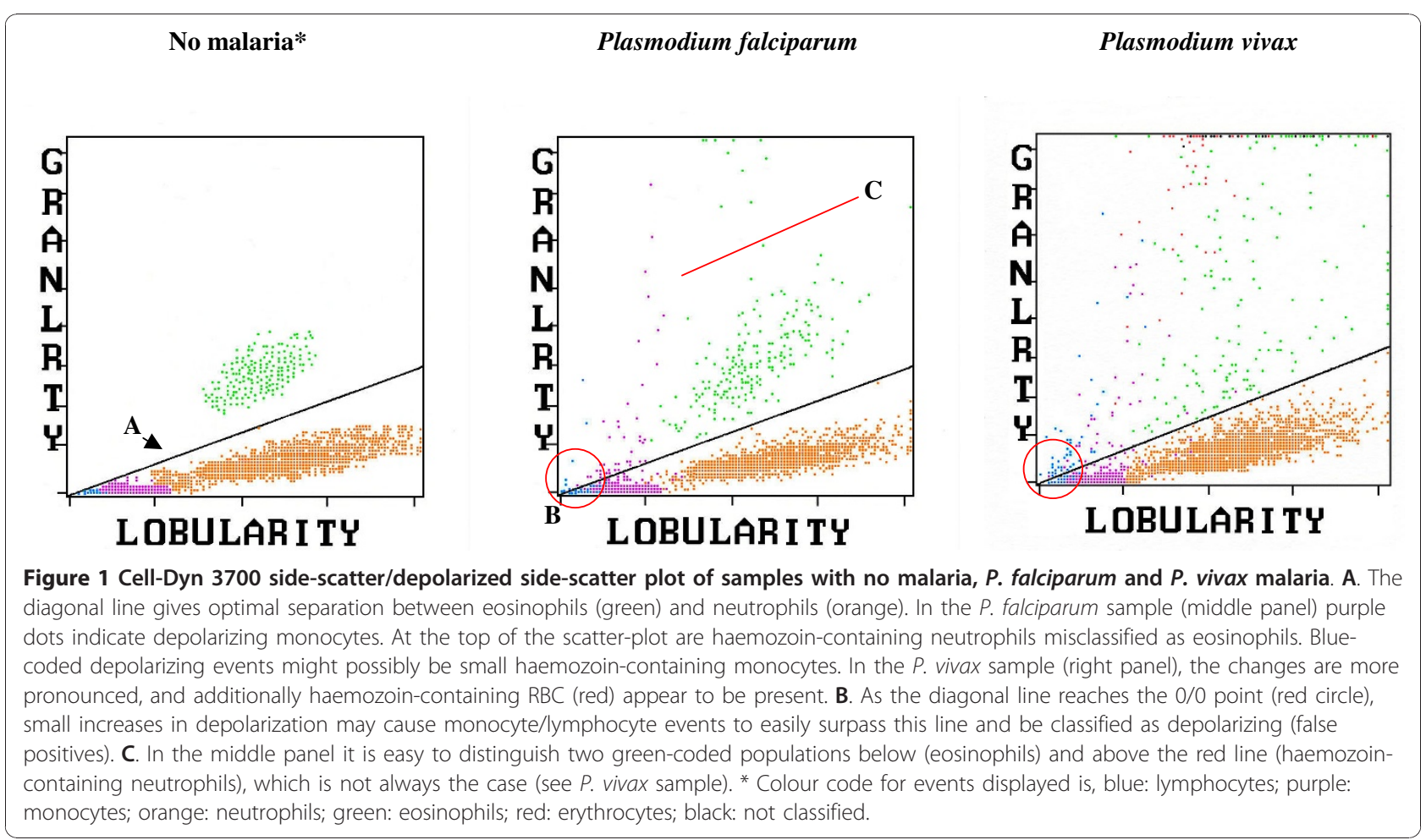

It appears that excitation light with a longer wavelength causes slightly stronger depolarization signals [29]. Of note, the CD 3000 series uses a $633 \mathrm{~nm}$ red laser, while the CD 4000 and CD Sapphire use a $488 \mathrm{~nm}$ blue laser for excitation. However, it is still unclear if this difference has any impact on the sensitivity for malaria detection.

\section{Cell-Dyn analysers - colour code for events and cells detected}

\section{Purple dots. Depolarizing monocytes}

The appearance of purple-coded events above the dynamic diagonal threshold line (Figure 1) separating eosinophils from granulocytes in the side-scatter/ depolarized side-scatter plot is the most studied malaria diagnosis criterion for the Cell-Dyn analysers (Table 1). However, this default diagonal line intersects at the $0 / 0$ value of the $x / y$-axis, potentially causing a progressive decrease in specificity as the $x$ and $y$ axes intersect when used as cut-off for malaria diagnosis. Depolarizing events that appear near this point (red circle in Figure 1), although showing low lobularity and granularity values (i.e. normal monocytes and lymphocytes) may still be present just above the dividing line, causing false positive results. Perhaps, this could explain an unusually low specificity of $25 \%$ reported in one recent study [33]. In fact, this finding has led some authors to construct horizontal lines for analysis [34], or an initial horizontal portion for the diagonal line (Figure 1); for example, only considering events above channel 25 on the $y$-axis [35,36], or even above channel 50 [30].

Green dots. Granulocytes miss-classified as eosinophils Highly depolarizing green-coded events could be indicative of haemozoin-containing granulocytes since it is unlikely that these events are just the result of eosinophil granules [34,37]. Applying the Cell-Dyn set-up to a Mo-Flow high speed sorter allowed to show that greencoded events, which fall outside a given area, are likely haemozoin-containing granulocytes [29]. However, it is difficult to establish a clear cut-off between eosinophils and other granulocytes with less haemozoin, which depolarize less (Figure 1C). These haemozoin-containing granulocytes might project into the eosinophil population and thus may not be singled-out. However, in one study the eosinophil-free region was optimized for malaria detection by using malaria negative samples, and when considering any green dot in this area as positive, the sensitivity and specificity were $85 \%$ and $96 \%$, respectively [34].

\section{Blue dots. Abnormal lymphocytes or small monocytes?}

Interestingly, in many cases blue-coded events, representing lymphocytes, show depolarization (Figure 1). In one study, this was observed in 77 of 152 children with malaria [34]. Yet, lymphocytes are not phagocytic cells. Although no study has looked systematically into this, it seems likely that the recent discovery of 


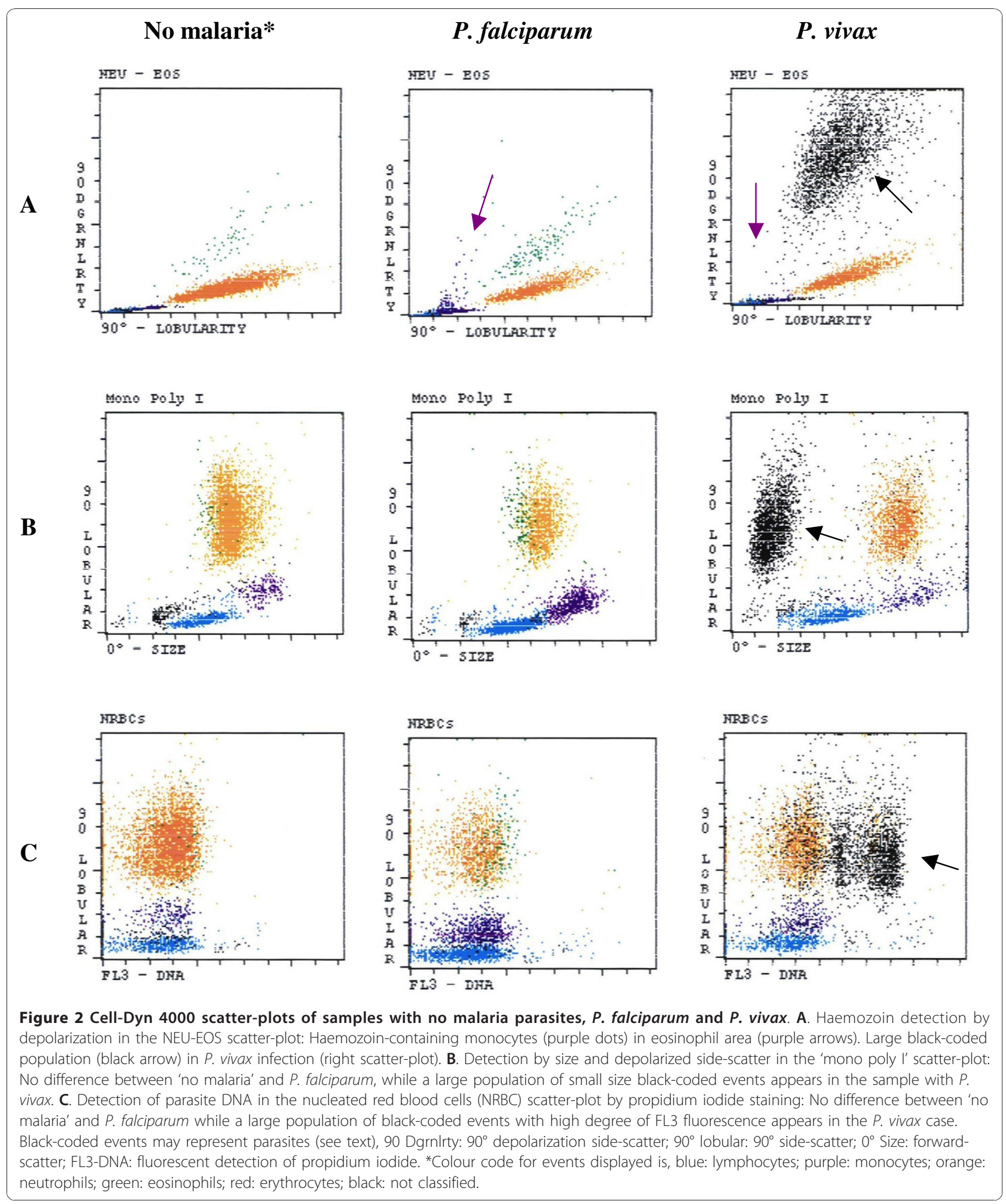


different monocyte subsets may offer an explanation [38], as some monocyte subpopulations may be rather small and show a round nucleus, similar to lymphocytes. The Cell-Dyn may thus miss-classify these cells as lymphocytes. If this is confirmed, depolarizing bluecoded events ought to be included as part of the sidescatter/depolarized side-scatter plot diagnostic criterion for malaria.

\section{Red dots and black dots. Haemozoin-containing parasites?}

One report using a CD 3700 has suggested that in blood with $P$. vivax parasites and osmotically-resistant RBCs, haemozoin inside infected erythrocytes may also be detected [31]. With the CD 3000, these events are correctly identified as RBC (red dots) (Figure 1). Using the CD 4000, in cases of $P$. vivax infections, large blackcoded populations have been observed, which usually indicate non-leucocytic events (Figure 2). These events could be caused by parasites since these populations are much smaller in size than any of the leukocyte populations [32,35,37]. However, it is unclear if they represent lysis-resistant haemozoin-containing erythrocytes or perhaps large parasites seen in mature forms (mature trophozoites, schizonts). The suspected nature of these events could explain why this pattern is more frequent in $P$. vivax infections, which have asynchronous parasitaemia and more circulating mature parasites rich in haemozoin [37].

\section{Cell-Dyn analysers and haemozoin-containing WBCs - studies on diagnostic accuracy}

The most-studied malaria-related abnormality for CellDyn analysers is the presence of abnormal monocytecoded depolarizing events (purple) in the side-scatter/ depolarized side-scatter plot (Table 1 and Additional File 1). The first published study, by Mendelow and colleagues in South Africa (1999), tested 224 blood samples from patients with suspected malaria (99\% with P. falciparum) and found that $\geq 1$ purple-coded event(s) above the diagonal eosinophil/granulocyte threshold line (Figure 1) had a sensitivity of $72 \%$ and a specificity of $96 \%$ [18]. However, the definition of what constitutes a CellDyn malaria-positive sample varies between studies, especially regarding the position of the cut-off line and the fact that multiple reference diagnosis tests are used (Table 1). Sensitivity in 13 studies ranged from $48.6 \%$ to $100 \%[18,27,30,32-37,39-43]$ and specificities from $25.3 \%$ to $100 \%$ [18,27,30,32-37,39-43] (Table 1). Some studies on imported malaria showed rather low values for sensitivity (Table 1); for example $48.6 \%$ found in Germany [27], 55\% found in South Africa [44], and 62\% in The Netherlands [36]. Interestingly, Mendelow and colleagues showed that sensitivity was $90 \%$ in black patients versus $43 \%$ in white patients [18]. The best explanation for this is that non-immune patients, more frequently white, might have very few circulating haemozoin-containing leukocytes when surpassing the pyrogenic threshold, i.e., at the time when malaria symptoms occur [27]. In line with this, the sensitivity in a study from Portugal was 95\% [39], with malaria occurring almost exclusively in black African immigrants from former colonies, with the possibility of residual immunity levels. Many presented rather late during their malaria episode, when the haemozoin burden would be expected to be higher. Grobusch and colleagues found that the sensitivity of the CD 3000 to detect malaria in semiimmune patients, as measured by indirect fluorescent malaria antibody test (titre $\geq 1: 40$ ), was $73.7 \%$ compared to $28.6 \%$ in non-immune patients [27]. This discrepancy was related to the concentration of haemozoin-laden macrophages in each group, with semi-immune and non-immune patients having a median relative frequency of $9 \times 10^{-4}$ and $1.5 \times 10^{-4}$ cells respectively[27]. Consequently, in most malaria-endemic countries, sensitivity values of $>90 \%$ were not uncommon (Table 1 ).

Contrary to sensitivity, values for specificity regularly reached $90 \%$ across studies, with many studies reporting figures close to $100 \%$ (Table 1). However, one outlier study reported a highly discrepant value of only $25 \%$ specificity, due to technical limitations when using the built-in diagonal separation line, as almost all false positives $(269 / 290)$ showed only a single depolarizing purple dot [33]. As explained above, these events would have counted as non-significant in most settings and this shortcoming can be corrected by using an initial horizontal portion for the separating line (Figure 1) $[30,35,36]$.

\section{Cell-Dyn analysers - further malaria-related changes}

Other malaria related abnormalities described only for the CD 4000 include abnormalities observed in other scatter-plots, especially the EOS-I scatter-plot, which shows granularity (depolarized side-scatter) versus size $\left(0^{\circ}\right.$-forward-scatter $)[32,35,37,41]$. Several studies reported the appearance of highly granular (depolarized side-scatter values above channel 50), green or blackcoded events clustered (as opposed to random) in the small-size range (low forward-scatter) [32,35,37]. Given the small size and high granularity of these events, they most likely correspond to haemozoin-laden mature parasites or haemozoin-rich red cell 'ghosts' [37]. Events in the depolarized side-scatter/forward-scatter plot (EOS-I, CD 4000) are more frequent with $P$. vivax $[35,37]$. Clustered events on the EOS-I scatter-plot have sensitivities that range from $57.1 \%$ to $93 \%$ for $P$. vivax but are as low as $0 \%$ to $1.5 \%$ for $P$. falciparum, and are near 100\% specific for both Plasmodium species [35,37]. Similar events can also be observed in the mono-poly I scatter-plot (side-scatter/forward-scatter plot) (Figure 2) 
[45]. Also, propidium iodide, used in the CD 4000 to detect nucleated RBC stains parasites, thus causing abnormal signals in the scatter-plots that register the FL3 signal (red fluorescence) (Figure 2) [37,45]. Interestingly, these events may also be more frequent in $P$. vivax infections $[37,45]$.

Finally, reticulocyte-associated changes have been reported, usually in P. falciparum samples [36,44], such as extra spikes in the reticulocyte histogram, pseudoreticulocytosis, and a high immature reticulocyte fraction $[41,44,46]$. One study evaluated $108 \mathrm{P}$. falciparuminfected samples and found a good correlation $\left(R^{2}=0.6\right)$ between parasitaemia and Cell-Dyn reticulocyte percentages [44], and all samples with a parasitaemia superior to $5 \%$ infected RBCs had an immature reticulocyte fraction $\geq 0.5$; of those with an immature reticulocyte fraction $\geq 0.5,81 \%$ had an isolated spike on the reticulocyte histogram [44]. However, due to expensive reagents, hardly any laboratory runs the haematology analyser in the reticulocyte mode on a routine basis, decreasing the utility of any malaria-related finding in the reticulocyte measurements.

\section{Cell-Dyn analysers - changes observed in P. vivax and other species}

The frequency and patterns of malaria-related events in the CD 4000 scatter-plots differ between Plasmodium species (Figure 2) $[32,35,37,45]$. As described above, small sized black-coded populations with high degree of depolarization were noted with increased frequency in $P$. vivax-containing samples. In one study using a $C D$ 4000, 12 out of 20 P. vivax-positive samples consistently showed depolarizing events after being depleted of WBC, suggesting that in $P$. vivax malaria these events may also be directly caused by parasites [32]. The same authors analysed serially diluted leukocyte depleted samples with a CD 4000 and determined a detection threshold for depolarizing events of $288 \pm 17.7$ parasites $/ \mu \mathrm{l}$ [32]. Another study also showed small clustered blackcoded events in the EOS-I scatter-plot (depolarized side-scatter/forward-scatter) being seen almost exclusively in $P$. vivax cases [37]. Given the small size and high depolarization values for these events, they were most likely caused by haemozoin-laden mature parasites or haemozoin-rich red cell 'ghosts' [37], coinciding also with the asynchronous parasitaemia of P. vivax. Plasmodium ovale and Plasmodium malariae infections have shown abnormal side-scatter/depolarized side-scatter plots $[36,40]$.

Cell-Dyn analysers and malaria detection - limitations and necessary improvements

Haemozoin ingested by neutrophils may be detected for up to a median of 72 hours and haemozoin ingested by monocytes up to a median of 216 hours according to each cell's circulating half life [47]. Although this could translate into false positives in areas of high transmission, as patients with recent episodes of malaria may still harbour these cells, studies from endemic areas have not reported low specificities (Table 1). Dromigny and colleagues found that the false positive rate among convalescent patients who could still have circulating haemozoin-laden phagocytes was $17.6 \%$; however, including these samples into the 'malaria negative' group only decreased specificity from $96.7 \%$ to $95.6 \%$ [30].

The detection threshold for malaria probably depends on total parasite burden and may vary with the CellDyn model used. One study reported a reduction in sensitivity from $72 \%$ down to $67 \%$ with parasitemias in the range of $0.1 \%-1 \%$, and further down to $50 \%$ with parasitaemias of less than $0.1 \%$ [41]. The total number of haemozoin-containing cells in the body and those analysed and represented by the instrument determine the sensitivity $[29,34]$. Using the Mo-Flow cell sorter and rare event analysis, the threshold for detection of malaria by the Cell-Dyn instruments was in the order of $2 \times 10^{-4}$ pigment-containing monocytes [29]. However, most of the Cell-Dyn 3000 instruments only analyse WBC in a given volume, with an upper limit of $10^{4}$ WBC. Not surprisingly, one study showed that only a mean of 1,364 monocytes (range: 230 to 3,660) were analysed in each sample $(\mathrm{n}=152)$, indicating an intrinsic limitation of detection of these instruments [34]. Furthermore and more importantly, not all analysed cells are shown on-screen, and screen resolution is inferior for the CD 3000 series where $140 \times 140$ pixels represent results from $256 \times 256$ channels (around 3.34 times less information resolution) [34].

Additionally, only the first 5,000 events analysed are used for the graphic display, and in the case of cells being superimposed, only one event is shown [34]. Results from a study in Gabon that used screenshots indicate that each side-scatter/depolarized side-scatter plot of the CD 3000 series contains only around 500 pixels, representing the analysed cells, with a data-loss, based on manual on-screen analysis, that may be as high as 90\% (Table 2) [34].

In summary, the CD instruments appear to detect malaria associated changes with a high degree of reliability, however, this depends so far on the meticulous observation of the described changes during validation of $C B C$ results (either on screen or print-out). Thus, laboratory staff ought to receive continuous training allowing them to recognize these changes. Obviously, it would be highly desirable if the manufacturer included analysis algorithms that would automatically flag suspicious samples. 
Table 2 Cell counts and data loss with a Cell-Dyn 3000 instrument

\begin{tabular}{lcccc}
\hline Cell type & $\begin{array}{c}\text { Mean cell count in CBC } \\
\text { result }\end{array}$ & $\begin{array}{c}\text { Mean number of cells } \\
\text { analysed }\end{array}$ & $\begin{array}{c}\text { Mean number pixels on } \\
\text { screen* }^{*}\end{array}$ & $\begin{array}{c}\text { Information (cell count) lost in scatter-plot } \\
\text { display (\%)** }\end{array}$ \\
\hline WBCs & $8675 / \mu \mathrm{L}$ & 9100 & 482 & 94.4 \\
Granulocytes & $3834 / \mu \mathrm{L}$ & 4174 & 348 & 90.9 \\
Lymphocytes & $2992 / \mu \mathrm{L}$ & 3068 & 22 & 99.3 \\
Monocytes & $1334 / \mu \mathrm{L}$ & 1379 & 58 & 95.7 \\
Eosinophils & $349 / \mu \mathrm{L}$ & 345 & 43 & 87.7
\end{tabular}

Data shown correspond to the mean values for 153 CBC results from malaria positive patients, obtained with a CD 3000 instrument in Lambaréné, Gabon. ${ }^{*}$ Coloured pixels indicate the events that represent analysed cells in the side-scatter/depolarized side-scatter plot (lobularity/granularity) on-screen (Figure 1). ** \% data lost $=1$ - (Mean number pixels on screen/Mean cell count in CBC result) $\times 100$. Screen images were analysed by taking a screenshot and counting the pixels using ImageJ image processing software.

\section{Coulter GEN.S and LH analysers}

Coulter GEN.S and LH 750 haematology analysers use Volume-Conductance-Scatter (VCS) technology to obtain 'positional parameters' of all WBC by measuring impedance for cell volume; radiofrequency conductivity for internal structure and nuclear characteristics; and flow cytometry-based helium-neon laser light scatter analysis for cellular granularity, nuclear lobularity and cell surface structure $[22,48]$. An initial study by Fourcade and colleagues (2004), using a GEN.S that included 89 participants suspected of having malaria $(28$ had $P$. falciparum and four had $P$. vivax) compared all positional parameters between malaria-negative and positive samples. They determined that the lymphocyte volume standard deviation (SD) and the monocyte volume SD were the most accurate for malaria detection [49]. These abnormalities reflect cellular anisocytosis, probably from activated monocytes as a response to the infection [48]. Fourcade and colleagues proposed a discriminant factor ('malaria factor' [48]) using the lymphocyte SD and monocyte SD values (Figure 3)[49]. Receiver operator curve (ROC) analysis determined an optimal cut-off value of 5.1 for a sensitivity and specificity of $96.9 \%$ and $82.5 \%$, respectively [49]. In a subsequent study with 275 participants suspected of malaria (147 with malaria), 1079 healthy volunteers and $51 \mathrm{HIV}$ infected patients without malaria, Briggs and colleagues calculated a malaria factor of 3.7 with a sensitivity and specificity of $98 \%$ and $94 \%$, respectively (Table 3) [48]. The malaria factor for $P$. falciparum, $P$. vivax, and $P$. ovale was 6.2, 5.9 and 5.7, respectively [48]. In both studies, some malaria-positive samples showed an extra peak in the WBC histogram at the $35 \mathrm{fl}$ threshold $[48,49]$. Briggs and colleagues determined that the malaria factor, in the absence of an extra peak in the WBC histogram, a platelet count $\geq 150 \times 10^{9} / \mathrm{l}$, eosinophils $>0.015 \%$, monocyte volume SD $<23.2 \mathrm{fl}$ and a mean volume for monocytes $<180 \mathrm{fl}$ had a negative predictive value of $99.7 \%$ [48]. Samples with a positive malaria factor had a parasitaemia ranging from $0.001 \%$ to $38.9 \%$ infected RBCs [48]. By incorporating of the calculation for the malaria factor into the Coulter analyser's Information Processing Unit or into the Laboratory Information System an automated malaria alarm for this type of analyser could be implemented.

\section{Sysmex XE-2100 analyser}

The Sysmex XE-2100 automated haematology analyser uses combined impedance and radiofrequency conductance detection, semiconductor diode laser light $90^{\circ}$ side-scatter (SSC) and $0^{\circ}$ frontal-scatter (FSC) detection, and polymethyne fluorescence nucleic acid staining $90^{\circ}$ side-fluorescence (SFL) detection. It measures 32 clinical variables, and graphs seven scatter-plots and two histograms $[22,50]$. Three scatter-plots have shown significant abnormalities in samples with malaria (Figure 4) [51].

\section{Abnormal DIFF, WBC/BASO and RET-EXT scatter-plots, and pseudoeosinophilia}

In South Korea, two case series, one with sixteen [52] and the other with three [53] P. vivax-infected patients, reported spuriously elevated eosinophil counts (pseudoeosinophilia) and abnormalities in the DIFF scatterplot consisting of additional blue, red or gray-coded grouped events, and a fusion of both neutrophil and eosinophil groups (Figure 4) [52,53]. Later, two studies in a malaria-endemic region in South Korea evaluated pseudoeosinophilia ( $>5 \%$ difference between the automated and manual eosinophil count) and DIFF scatterplot abnormalities for $P$. vivax diagnosis against thick film [54], or against thick film and real-time polymerase chain reaction (RT-PCR) [55] (Table 4). In the first study by Huh and colleagues [54], pseudoeosinophilia and abnormal DIFF scatter-plot alone yielded sensitivities of $39 \%$ and $52 \%$, respectively, with no change in specificity. In the more recent study by Yoo and colleagues [55], the positive and negative predictive values were $97.9 \%$ and $86.2 \%$, respectively, and an abnormal DIFF scatter-plot alone yielded a marginal sensitivity of $16 \%$. This large decrease in sensitivity for DIFF abnormalities could arise from the lack of a consensus 


\section{Cell-Dyn series analysers}

\section{Abnormal side-scatter/depolarized side-scatter plot (Figure 1)}

- $\quad \geq 1$ purple or black event(s) above a diagonal that separates eosinophils (high granularity) from neutrophils [28, 32], or either green or black events with a granularity (depolarization) higher than normal eosinophil cluster [34].

\section{Abnormal depolarized side-scatter/forward-scatter plot (EOS-I) (CD 4000) (Figure 2)}

- $>1$ clustered black-coded events left to channel 75 of the abscissa and above channel 50 of the ordinate, usually in $P$. vivax malaria [35].

Other scatterplots including FL3 values

- Clustered black-coded events of high fluorescence (FL3) and either, small size [37, 45] or high lobularity.

\section{Coulter GEN·S and LH 750 analysers}

Malaria factor [48-49]

$$
\frac{\text { Lymphocyte volume } S D \times \text { Monocyte volume } S D}{100}=\text { Malaria factor }
$$

- Suspect malaria if factor is above cut-off value determined by ROC curve analysis. This could vary depending on the clinical setting, thus implementing an individual laboratory cut-off value may achieve a higher accuracy. Cut-offs given by two studies are 3.7 [48] and 5.1 [49].

\section{Sysmex XE-2100 analyser}

Univariate observer-dependent criteria $\left(U-O D_{P v}\right)($ Figure 3) [51]

- 'General XE-2100 P. vivax pattern'

Multivariate observer dependent criteria $\left(M-O D_{P v}\right)$ - Malaria Score (diagnosis $\geq 4 / 11$ points) (Figure 3) [51]

- $\quad \geq 7$ pixels in the $\mathrm{WBC} / \mathrm{BASO}(\mathrm{III})$, three points.

- Number of granulocyte-coded DIFF abnormalities (out of 10), one point each.

Non-observer dependent models $(\mathrm{N}-\mathrm{OD} 1) *[51]$

- P. vivax $\mathrm{N}-\mathrm{OD} 1_{P v}: \frac{1}{1+e^{-[-74.130-0.205 \text { Plateletcrit }+0.046 \Delta D I F F / W B C+0.045 \text { LYMPHY }]}}=\geq 0.42$

- P. falciparum N-OD $1_{P f:} \frac{1}{1+e^{-[-31.024-0.018 P L T O+0.502 R D W S D+0.019 L Y M P H Y]}}=\geq 0.29$

\section{Pseudoeosinophilia:}

- Gap $\geq 20.9 \%$ between the automated and manual eosinophil count [51, 54].

Figure 3 Summary of proposed malaria diagnostic criteria for the Abbott Cell-Dyn, Coulter GEN.S and LH 750, and Sysmex XE-2100 haematology analysers. *Non-Observer Dependent ( $\mathrm{N}-\mathrm{OD}$ ) models use the logistic regression predicted probability equation:

$\frac{1}{1+e^{-\left(\beta_{0}+\beta_{1} x_{1}+\beta_{2} x_{2}+\ldots+\beta_{n} x_{n}\right)}}=\mathrm{PP}$, where $\beta_{0}$ and $\beta_{1,2, \ldots n}$ correspond to the intercept and variable's coefficients, $x_{1,2, \ldots n}$ are the values

for each variable obtained for each individual blood sample, and PP is the predicted probability for which the optimal diagnosis cut-off is show in the figure [51]. Samples with a 'Predicted Probability' (PP) above the cut-off are considered positive for malaria and could be flagged by a programmed Laboratory Information System. Variables for N-OD1 $p_{v}$ : plateletcrit; ratio between DIFF channel and total WBC count ( $\triangle \mathrm{DIFF}$ WBC); and mean value of LYMPH-Y in arbitrary units (LYMPHY). Variables for N-OD1pf. Optical platelet count (PLTO); red cell distribution width SD (RDWSD); and LYMPH-Y in arbitrary units (LYMPHY). 
Table 3 Summary of studies evaluating malaria diagnostic accuracy of the Coulter GEN.S and LH 750 analysers

\begin{tabular}{|c|c|c|c|c|c|c|}
\hline $\begin{array}{l}\text { First author, } \\
\text { year and } \\
\text { country }\end{array}$ & Number of participants and diagnoses & Standard reference test & Blinding & $\begin{array}{l}\text { Malaria } \\
\text { factor }\end{array}$ & $\begin{array}{l}\text { Sensitivity } \\
\%\end{array}$ & $\begin{array}{l}\text { Specificity } \\
\%\end{array}$ \\
\hline $\begin{array}{l}\text { Fourcade, } \\
\text { 2004, France } \\
\text { and Spain [49] }\end{array}$ & Total: 89 , P. falciparum: 28 , P. vivax: 4 & $\begin{array}{l}\text { Microscopy, HRP2+ pan-malarial } \\
\text { antigen (Binax Now) }\end{array}$ & - & 5.1 & 82.5 & 96.9 \\
\hline $\begin{array}{l}\text { Briggs, 2006, } \\
\text { South Africa } \\
\text { and England } \\
{[48]}\end{array}$ & $\begin{array}{l}\text { Total: } 1354 \text {, healthy: } 1079 \text {, febrile: } 135, \text { HIV } \\
\text { infected: } 51 \text {, P. falciparum: } 120 \text {, P. vivax: } 11 \text {, } \\
\text { P. ovale: } 7, \text { P. malariae: } 1 \text {, mixed P. falciparum and } \\
\text { P. vivax: } 1\end{array}$ & $\begin{array}{l}\text { Microscopy, QBC, HRP2+ pan- } \\
\text { malarial antigen (Binax Now), } \\
\text { PfHRP2 (MAKROmed), P-LDH } \\
\text { (optiMAL) }\end{array}$ & - & 3.7 & 98 & 94 \\
\hline $\begin{array}{l}\text { Kang, 2008, } \\
\text { South Korea } \\
{[66]^{*}}\end{array}$ & Total: 395, P. vivax: 68 & Microscopy & ** & 4.57 & 81.8 & 72.3 \\
\hline
\end{tabular}

${ }^{*}$ Article in Korean, only abstract in English. ${ }^{* *}$ Could not be assessed.

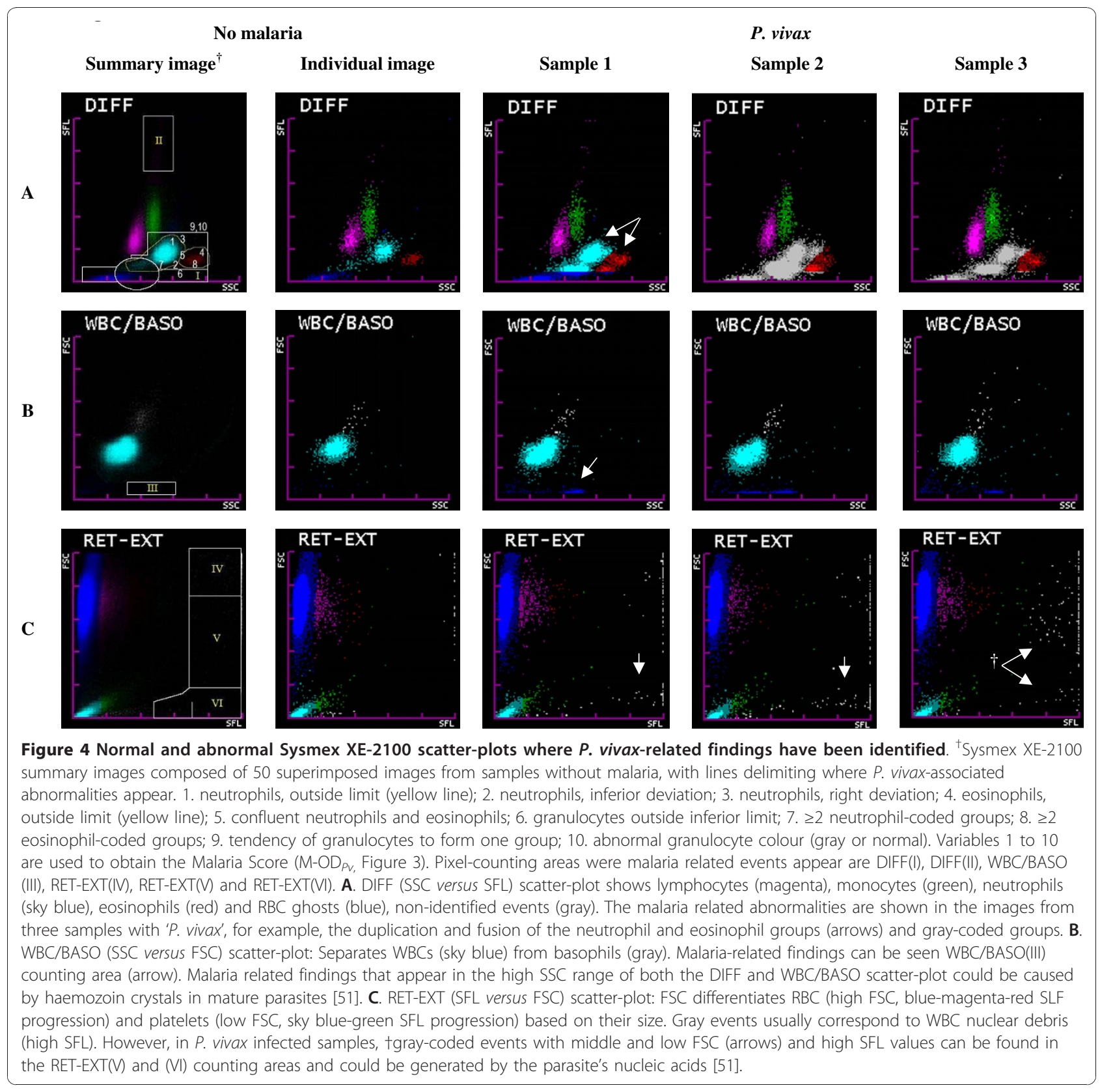


Table 4 Summary of studies evaluating the malaria diagnostic accuracy of the Sysmex XE-2100 analyser

\begin{tabular}{|c|c|c|c|c|c|c|}
\hline $\begin{array}{l}\text { First author, year and } \\
\text { country }\end{array}$ & $\begin{array}{l}\text { Number of participants } \\
\text { and diagnoses }\end{array}$ & Blinding & \multicolumn{2}{|c|}{ Index test criterion } & $\begin{array}{l}\text { Sensitivity } \\
\%\end{array}$ & $\begin{array}{l}\text { Specificity } \\
\%\end{array}$ \\
\hline Huh, 2008, South Korea [54] & Total: 463, P. vivax: 144 & - & \multicolumn{2}{|c|}{$\begin{array}{l}>5 \% \text { pseudoeosinophilia and/or an abnormal DIFF }_{\text {scatter-plot }^{\dagger}}\end{array}$} & 69.4 & 100 \\
\hline Yoo, 2010, South Korea [55]* & Total: 1801, P. vivax: 413 & & & & 46.2 & 99.7 \\
\hline \multirow[t]{7}{*}{$\begin{array}{l}\text { Campuzano-Zuluaga, 2010, } \\
\text { Colombia [51] }\end{array}$} & $\begin{array}{l}\text { Total: } 158, \text { P. falciparum: } \\
30, \text { P. vivax: } 65,63 \text { febrile } \\
\text { patients } \\
\text { Validation control group } \\
\text { including healthy and } \\
\text { febrile participants: } 161\end{array}$ & + & Model" & Variables (Figure 4) & & \\
\hline & & & $\mathrm{U}-\mathrm{OD}_{P_{v}}{ }^{\ddagger}$ & 'XE-2100 P. vivax pattern' & 96.9 & 93.6 \\
\hline & & & $M-O D_{p_{v}}^{* *}$ & $\begin{array}{l}\text { Number of granulocyte DIFF } \\
\text { abnormalities } \\
\geq 7 \text { pixels in the WBC/BASO(III) }\end{array}$ & 95.4 & 98.4 \\
\hline & & & $\mathrm{N}-\mathrm{OD} 1_{p_{v}}$ & $\begin{array}{l}\triangle D I F F / W B C \\
\text { Plateletcrit } \\
\text { LYMPH-Y }\end{array}$ & 94.3 & 95.1 \\
\hline & & & $\mathrm{N}-\mathrm{OD} 2 p_{p_{v}}$ & $\begin{array}{l}\text { PLT-O } \\
\text { Pixels WBC/BASO(III) }\end{array}$ & 96.8 & 96.8 \\
\hline & & & $\mathrm{N}-\mathrm{OD} 1_{\rho f}$ & $\begin{array}{l}\text { PLT-O } \\
\text { RDW-SD } \\
\text { LYMPH-Y }\end{array}$ & 93 & 81 \\
\hline & & & $\mathrm{N}-\mathrm{OD} 2_{p f}$ & $\begin{array}{l}\text { PLT-O } \\
\text { RDW-SD Pixels WBC/BASO(III) }\end{array}$ & 86 & 90 \\
\hline
\end{tabular}

* All studies use microscopy as reference test for malaria diagnosis, except Yoo and colleagues study that also use real time quantitative PCR (RT-PCR). ${ }^{\dagger}$ An abnormal DIFF scatter-plot corresponds to extra blue, red or gray-coded groups in the DIFF scatter-plot (Figure 4). " All N-OD models use continuous variables and are designed to compute a predicted probability of malaria obtained from the logistic regression analyses as shown in Figure 3 . ${ }^{\ddagger}$ The recognition of a 'general $X E-2100 P$. vivax pattern' seen in the DIFF, WBC/BASO and RET-EXT scatter-plots corresponds to the univariate observer-dependent model [U-OD $\left.P_{P v}\right]$. M-OD $P_{P v}$ : The multivariate observerdepend model, by means of a 'malaria score' quantifies several abnormalities seen in the U-OD $P_{v v}{ }^{* *}$. vivax Malaria Score: ' $\geq 7$ pixels in the WBC/BASO(III)' (3 points), 'number of granulocyte-coded DIFF abnormalities' (10 variables; 1 point per variable), with $\geq 4$ points being diagnostic. N-OD1: Non-observer dependent models that use built-in XE-2100 variables, for $P$. vivax $\left(P_{v}\right)$ and $P$. falciparum $\left({ }_{P f}\right)$. N-OD2: Non-observer dependent models that use built-in XE-2100 variables and the WBC/BASO(III) pixel count (Figure 4$)$, for $P$. vivax $\left(p_{v}\right)$ and $P$. falciparum $\left(p_{f}\right)$. PLT-O: Optic platelet count. RDW-SD: Red cell distribution width SD.

definition for this diagnosis criterion, as well as difficulty with, and subjectivity in manually evaluating these patterns that could have resulted in a classification bias towards highly abnormal patterns in the latter study [55]. Regarding pseudoeosinophilia, a more recent study suggests a higher optimal cut-off of $21 \%$, for $P$. vivax, with clinically insufficient accuracy (57.5\%) [51]. Furthermore, pseudoeosinophilia warrants little clinical usefulness, since the microscopy required for its calculation would equally enable the visualization of parasites. It is also noteworthy that abnormalities in the DIFF scatter-plot and WBC counts of the XE-2100 have also been reported in samples with Candida spp. [26].

In a recent study in Colombia, Campuzano-Zuluaga and colleagues found that $P$. vivax samples also showed salient abnormalities in the WBC/BASO and RET-EXT scatter-plots (Figure 4) [51]. For the WBC/BASO(III) counting area, $\geq 7$ blue-coded events (pixels) had a sensitivity and specificity of $97 \%$ and $94 \%$, respectively, for $P$. vivax; and $\geq 3$ pixels had a sensitivity and specificity of $60 \%$ and $67 \%$, respectively, for P. falciparum. For the RET-EXT(V and VI) counting areas, $\geq 1$ linear or clustered gray events (pixels) had a sensitivity and specificity of $77 \%$ and $76 \%$, respectively, for P. vivax (Figure 4)
[51]. This study found a significant moderate-to-high correlation for most abnormalities in the DIFF, WBC/ BASO and RET-EXT scatter-plots and the concentration of $P$. vivax mature trophozoites, schizonts or gametocytes (Figure 4) [51]. However, studies tailored to establish the nature of these abnormalities are needed, for example by measuring leukocyte-reduced samples with synchronized parasitaemia.

\section{An algorithmic approach to malaria detection with the XE-2100}

The numerous XE-2100 variables affected by malaria parasites, up to 35 variables in $P$. vivax infections, make their individual use for malaria diagnosis cumbersome and unpractical [51]. However, by mathematically combining variables with the highest accuracy into a single diagnostic criterion, the method can be optimized and simplified into a robust numerical algorithm, computable by a Laboratory Information System or even by the Sysmex Information Processing Unit in the future. With this premise, Campuzano-Zuluaga and colleagues carried out a study where diagnostic models for both $P$. vivax $(\mathrm{n}=65)$ and $P$. falciparum $(\mathrm{n}=30)$ where developed and evaluated for accuracy against 63 samples from febrile patients, and partially 
validated against samples from a composite group of 161 febrile patients and healthy individuals (Table 4). They selected the best malaria-predictor variables and in a stepwise approach created several multivariate logistic regression prediction models. The optimal diagnostic 'predicted probability' (PP, numerical output of the model) as determined by ROC curve analysis was used as the diagnosis criterion for each model (positive: $\geq$ optimal PP; negative: $<$ optimal PP) (Figure 3 and Table 4) [51]. Besides creating two observer-dependent models for $P$. vivax diagnosis, which require trained personnel to evaluate them manually, the authors developed two non-observer dependent (N-OD) models for each species. One used XE-2100 builtin variables (N-OD1), and the other one used built-in variables and new scatter-plot variables defined by the authors (N-OD2) (Figure 3, Figure 4 and Table 4) [51]. These models could allow for the systematic screening and detection of samples with malaria in a case-by-case fashion without the intervention of laboratory personnel in the procedure, and their accuracies make them promising for clinical application and testing in population-based studies (Table 4).

The $\mathrm{N}-\mathrm{OD} 1_{P v}$ and $\mathrm{N}-\mathrm{OD} 1_{P f}$ models include the increase in the mean number of events detected in the LYMPH-Y ( $y$ axis) channel [51], which has shown a moderate association with ring forms of $P$. $\operatorname{vivax}\left(R^{2}=\right.$ $0.206, P=0.01)$ and $P$. falciparum $\left(R^{2}=0.305, P=\right.$ $0.03)$ parasites [51]. The $\triangle \mathrm{DIFF} / \mathrm{WBC}$ variable in the $\mathrm{N}$ $\mathrm{OD} 1_{P v}$ corresponds to the ratio between the WBC counts in the DIFF channel over the total WBC count multiplied by $10^{3}$ and may relate to an excess count of malaria related events in the DIFF channel [51]. The NOD2 model for both species include the WBC/BASO (III) pixel count which was found to be the best malaria-diagnostic variable alone and in combination with other variables (e.g. thrombocytopenia) (Table 4 and Figure 4) [51]. Events in the WBC/BASO(III) are not currently quantified by the XE-2100, and it is likely that the direct measurement of these events could increase its analytic sensitivity, thus allowing for a direct detection by the instrument to generate an alert signal. Some of the findings for the XE-2100 could potentially be applicable for the Sysmex XS and XT series analysers since they use similar technology [56].

\section{Future directions}

Although current haematology analysers are not specifically designed to detect malaria-related abnormalities, most studies have found sensitivities that comply with WHO malaria-diagnostic guidelines: i.e., $\geq 95 \%$ in samples with $>100$ parasites/ $\mu \mathrm{l}$ [57]. The eventual incorporation of a 'malaria alert' into modern analysers would allow for an automated and adjuvant diagnostic method in the workup of febrile patients possibly infected with malaria, especially in scenarios with low pre-test probability for the disease.

\section{Detection of unsuspected malaria-infected patients}

One of the most important advantages of blood cell analysers is that it would allow for a timely diagnosis of clinically unsuspected malaria cases which otherwise could go undetected leading to adverse clinical outcomes [14]. Initially, a case series by Hänscheid and colleagues reported two 'unsuspected' P. falciparum and Plasmodium ovale infected patients that were diagnosed by identifying depolarizing events in the side-scatter/ depolarized side-scatter plot of a CD 3500 [58]. In another study by Hänscheid and colleagues in Portugal, six patients with clinically unsuspected imported malaria were diagnosed within a 5-month period [39]. For the XE-2100 analyser, Pinter and colleagues in Hungary reported a patient unsuspected of having malaria and later being diagnosed with a $P$. vivax and Plasmodium malariae co-infection based on an abnormal DIFF scatter-plot [11]. For the Coulter analysers, Briggs and colleagues found that seven microscopy-negative samples, but positive by fluorescence microscopy and/or immunochromatography, all had a malaria factor $\geq 3.7$ [48].

Consequently, appropriate training of laboratory personnel which validates $\mathrm{CBC}$ may allow them to recognize malaria-related changes and request appropriate malaria diagnostic test to confirm the diagnosis. Certainly, automatic flags, either generated by the instrument or the Laboratory Information System would increase the detection of clinical unsuspected cases and would be especially helpful in the developed world where the use of haematology analysers is standard of care, and also in most cities of the developing world where their use is increasingly frequent.

\section{Automation}

Automation by means of a laboratory Information System could be achieved for diagnostic criteria formulated as numerical computations such as the 'malaria factor' obtained for the Coulter GEN.S and LH $750[48,49]$, and the N-OD $1_{P v}$ and N-OD $1_{P f}$ models for the Sysmex XE2100 (Figure 3) [51]. Further development of this diagnostic strategy is needed and would require validation of the models proposed for both Coulter and Sysmex analysers in a wide range of clinical scenarios where other haematologic pathologies may potentially cause false positive results (thrombocytopenia, anaemia or WBC anomalies). The automated computation of multivariate criteria (i.e., considering thrombocytopenia, anaemia and other malaria-related variables) could lead to robust algorithms and a cheap and effective means to screening large number of samples and flag malaria in a case-by-case fashion. 
Improvement of analytic sensitivity and specificity

Since 1980, flow cytometry has been used to detect Plasmodium spp. [59] and detection of haemozoin-laden monocytes [29] and the parasite's fluorescence-tagged DNA has been achieved $[19,60]$. Modern flow cytometry-based haematology analysers could make this technology more accessible for malaria detection. New generation analysers could be built and programmed to specifically detect malaria-related abnormalities and generate accurate malaria-specific alarms. This strategy could improve their analytic sensitivity. For example, one study found that the threshold for malaria detection by a FACStar flow cytometer (Beckton-Dickinson, Mountain View, CA) using fluorescent Hoechst 33258 DNA tagging was $\sim 50$ parasites/ $\mu$ l (approximately $\sim 0.001 \%$ of infected erythrocytes) [61]. Another study using an experimental Sysmex SIF cytometer (SIF prototype, Sysmex Corporation, Kobe, Japan), a specific cell lysis detergent and nucleic acid fluorescence tagging, was able to detect and differentiate $P$. falciparum parasites by stage with an inferior limit of detection of $0.002 \% \sim 0.003 \%$ infected erythrocytes [60]. This last study hints to the potential of flow cytometry not only to detect a parasitaemia at the range of current expert microscopy, but also to the capacity of these instruments to different parasite forms according to stage of maturity [60].

\section{Malaria during pregnancy screening using haemozoin- laden monocyte detection}

Cell-Dyn detection of depolarizing events could aid in the detection of malaria in pregnant patients. Hänscheid and colleagues assessed the diagnostic accuracy of sidescatter/depolarized side-scatter-plot depolarizing events detected by a CD 3000 to diagnose malaria in pregnant patients (Table 1$)$. This study found that $23.9 \%(\mathrm{n}=$ 164) were false positives when compared to thick film. However, of these, 37 were further evaluated using PCR, and $14 \%(n=5)$ where found to be true positives [43]. Placental sequestration of parasites decreases the diagnostic yield of microscopy [62]; however, circulating haemozoin-laden macrophages may still be detected by the Cell-Dyn, potentially allowing for detection during prenatal control in malaria endemic regions [43], where CBC counts are available.

\section{Haemozoin burden and disease severity}

Haemozoin load is related to severity and chronicity of malaria, and thus detection and quantification of haemozoin-laden monocytes and granulocytes with the Cell-Dyn instruments could provide a surrogate laboratory marker for disease severity $[47,63]$. Side-scatter/ depolarized side-scatter plot depolarizing events correlate with severe anaemia [42], and one study from
Gabon reported more depolarizing green-coded events in children with severe P. falciparum malaria [34]. In fact, microscopic determination of these pigment containing cells appears inadequate as severity marker [64], and this may be related to the inherent limitations of microscopic observation, such as the small number of cells that can be observed [65]. Flow cytometry-based cell counts done by haematology analysers could overcome this problem by achieving higher cell counts.

\section{Conclusions}

The early detection of malaria is life-saving. Most health personnel are trained to consider malaria in febrile patients arriving from endemic regions; however, in settings with low pre-test probability for malaria, the diagnosis may be initially overlooked. Malaria detection with haematology analysers, as a by-product of its main purpose, the CBC analysis, can be useful as an adjuvant diagnostic tool in the work-up of febrile patients. Ideally, a flag for malaria could be incorporated and used to guide microscopic evaluation of the patient's blood to establish the diagnosis and start treatment promptly. Automation of a malaria alarm is currently possible for the Coulter GEN.S and LH 750, and for the Sysmex XE-2100 analysers with the help of a Laboratory Information System, though these numerical diagnostic criteria should be validated against population-based samples. Participation of the industry is pivotal for these developments and it would be desirable that haematology analyser manufacturers would be open to evaluate and include algorithms in their instruments that might allow to flag samples with a high suspicion of malaria; a strategy which could potentially assist in generating more accurate algorithms in otherwise simpler devices.

\section{Additional material}

Additional file 1: Expanded Table 1 that includes reference diagnostic tests used, blinding status, and observations for each study.

\section{Abbreviations (alphabetical)}

ACT: Artemisinin Combination Therapy; CBC: complete blood count; CD: Cell-Dyn; DNA: deoxyribonucleic acid; FSC: $0^{\circ}$ frontal-scatter detection by the Sysmex XE-2100; HIV: Human Immunodeficiency Virus; HRP2: P. falciparum histidine-rich protein 2; ICT: immunochromatography; LDH: lactate dehydrogenase; $\mathrm{M}-\mathrm{OD}_{p_{v}}$ : multivariate observer-dependent diagnostic model for $P$. vivax or 'malaria score' which consists of the addition of several variables (' $\geq 7$ pixels in the WBC/BASO(III)' [3 points], 'number of granulocytecoded DIFF abnormalities' [10 variables; 1 point per variable]), with $\geq 4$ points being diagnostic; N-OD: non observer-dependent malaria diagnostic model based on logistic regression where the independent variables are obtained from the data gathered from each blood analysis and the outcome or dependent variable is the predicted probability (PP) for malaria that is dichotomized to positive or negative for malaria based on the optimal PP 
obtained by ROC analysis; N-OD1: N-OD model that only uses raw numerical variables given by the information processing unit of the Sysmex as independent variables; $\mathrm{N}-\mathrm{OD} 1_{p_{v}}$ and $\mathrm{N}-\mathrm{OD} 1_{p f}$ are the models for $P$. vivax and P. falciparum, respectively; N-OD2: N-OD diagnostic model that uses raw numerical variables given by the information processing unit of the Sysmex as well as pixel counts in the WBC/BASO(III) counting area as independent variables; $\mathrm{N}-\mathrm{OD} 2_{p_{v}}$ and $\mathrm{N}-\mathrm{OD} 2_{p f}$ are the models for $P$. vivax and $P$. falciparum respectively; PCR: polymerase chain reaction; PLT-O: optic platelet count; PP: predicted probability for malaria obtained from the logistic regression model; QBC: quantitative buffy coat. RBC: red blood cell(s); RDT: Rapid Diagnostic Tests (for malaria); RDW-SD: The RBC histogram peak height is assumed to be $100 \%$, the distribution width at the $20 \%$ frequency level (y axis of histogram) is RDW-SD (distance between intersections of histogram and a line extended from the $20 \%$ frequency), expressed in femtoliters; ROC: receiver operator curve; RT-PCR: real-time polymerase chain reaction; SD: standard deviation; SFL: $90^{\circ}$ side-fluorescence detection by the Sysmex XE-2100; SSC: $90^{\circ}$ side-scatter detection by the Sysmex XE-2100; U-ODPv: univariate observer-dependent diagnostic model for $P$. vivax which consists of the recognition of a general pattern of abnormalities on several of the Sysmex XE-2100 scatter-plots; VCS: Volume Conductance-Scatter; WBC: white blood cell(s). WHO: World Health Organization; The following acronyms are product-specific and defined as follows (alphabetical): $\triangle D I F F / W B C$ : Ratio between the WBC count in the DIFF channel over the total WBC count multiplied by $10^{3}$; DIFF: SSC/SFL WBC separation scatter-plot (Sysmex XE-2100); EOS-I: frontal/depolarized side-scatter WBC separation plot (CellDyn 4000); LYMPH-Y: mean number of events detected in the LYMPH-Y (y axis) channel; NEU-EOS: side-scatter/depolarized side-scatter WBC separation plot (Cell-Dyn 4000); RET-EXT: SFL/FSC 'extended reticulocyte' scatter-plot that shows erythrocytes and platelets with varying concentration of nucleic acids (Sysmex XE-2100); WBC/BASO: SSC/FSC WBC separation scatter-plot (Sysmex XE-2100).

\section{Competing interests}

GCZ, TH and MPG: All authors declare that they have no competing financial or any other interest in relation to their work.

\section{Authors' contributions}

GCZ conceived the paper, took the lead in conception and design, and led the drafting of the paper. TH and MPG contributed significantly to the conception and design, and to the writing of the paper. All authors have read and approved the final version of the paper.

\section{Acknowledgements}

We thank Ana Isabel Toro of the Editora Médica Colombiana (Edimeco), Colombia, for her thoughtful comments and review of the manuscript draft.

\section{Author details}

'Grupo Malaria, Facultad de Medicina, Universidad de Antioquia, Calle 62 \#52-59, Lab 610, Medellin, Colombia. 'Laboratorio Clínico Hematológico, Carrera 43C No. 5-33, Medellín, Colombia. ${ }^{3}$ Instituto de Microbiologia and Instituto de Medicina Molecular, Faculdade de Medicina, Av. Prof. Egas Moniz, 1649-028 Lisbon, Portugal. ${ }^{4}$ Infectious Diseases, Tropical Medicine and AIDS, Division of Internal Medicine, Academic Medical Centre, University of Amsterdam, Meibergdreef 9, PO Box 22660, 1100 DE Amsterdam, The Netherlands. ${ }^{5}$ Institute of Tropical Medicine, University of Tübingen, Germany. ${ }^{6}$ Division of Infectious Diseases, Department of Internal Medicine, Faculty of Health Sciences, University of the Witwatersrand, Johannesburg, South Africa.

Received: 21 September 2010 Accepted: 30 November 2010 Published: 30 November 2010

\section{References}

1. Giemsa G: Eine Vereinfachung und Vervollkommnung meiner Methylenblau-Eosin-Färbemethode zur Erzielung der RomanowskyNocht'schen Chromatinfärbung. Centralblatt für Bakteriologie 1904, 32:307-313.

2. Wongsrichanalai C, Barcus MJ, Muth S, Sutamihardja A, Wernsdorfer WH: A review of malaria diagnostic tools: microscopy and rapid diagnostic test (RDT). Am J Trop Med Hyg 2007, 77:119-127.
3. WHO: New perspectives. Malaria Diagnosis. Report of a Joint WHO/USAID Informal Consultation 25-27 October 1999 Geneva: World Health Organization; 2000

4. Gautam AS, Sharma RC, Bhatt RM, Gupta DK: Microscopic diagnosis of malaria in Kheda district of Gujarat. Indian J Malariol 1992, 29:83-87.

5. Durrhelm DN, Becker PJ, Billinghurst K, Brink A: Diagnostic disagreementthe lessons learnt from malaria diagnosis in Mpumalanga. $S$ Afr Med J 1997, 87:609-611.

6. Milne LM, Kyi MS, Chiodini PL, Warhurst DC: Accuracy of routine laboratory diagnosis of malaria in the United Kingdom. J Clin Pathol 1994, 47:740-742.

7. Hanscheid T: Diagnosis of malaria: a review of alternatives to conventional microscopy. Clin Lab Haematol 1999, 21:235-245.

8. WHO: Guidelines for the treatment of malaria. Geneva: World Health Organization;, 22010.

9. Grobusch MP, van Vugt M: Malaria therapy: Where do we stand , what next? Future Microbiology 2010, 5:1147-1449.

10. WHO: World malaria report 2008. Book World malaria report 2008. 2 edition. World Health Organization Geneva; 2008.

11. Pinter E, Szabo O, Tdorova R, Varnai Z, Banhegyi D: Relapse of Plasmodium vivax and recrudescence of Plasmodium malariae malaria as detectes by Sysmex XE 2100 fully automated blood cell analyzer. Sysmex Journal International 2007, 17:102-105.

12. Durante Mangoni E, Severini C, Menegon M, Romi R, Ruggiero G, Majori G: Case report: An unusual late relapse of Plasmodium vivax malaria. Am J Trop Med Hyg 2003, 68:159-160.

13. Day JH, Behrens RH: Delay in onset of malaria with mefloquine prophylaxis. Lancet 1995, 345:398.

14. Newman RD, Parise ME, Barber AM, Steketee RW: Malaria-related deaths among U.S. travelers, 1963-2001. Ann Intern Med 2004, 141:547-555.

15. Kain KC, Harrington MA, Tennyson S, Keystone JS: Imported malaria: prospective analysis of problems in diagnosis and management. Clin Infect Dis 1998, 27:142-149.

16. Graham M: The Coulter principle: foundation of an industry. JALA 2003, 8:72-81.

17. Shapiro MF, Greenfield S: The complete blood count and leukocyte differential count. An approach to their rational application. Ann Intern Med 1987, 106:65-74

18. Mendelow BV, Lyons C, Nhlangothi P, Tana M, Munster M, Wypkema E, Liebowitz L, Marshall L, Scott S, Coetzer TL: Automated malaria detection by depolarization of laser light. Br J Haematol 1999, 104:499-503.

19. Wongchotigul V, Suwanna N, Krudsood S, Chindanond D, Kano S, Hanaoka N, Akai Y, Maekawa Y, Nakayama S, Kojima S, Looareesuwan S: The use of flow cytometry as a diagnostic test for malaria parasites. Southeast Asian J Trop Med Public Health 2004, 35:552-559.

20. Coulter WH: Means for counting particles suspended in fluid. US Patent 2,656,508, filed August 27, 1947 and issued October 20, 19531953.

21. Houwen B: The differential cell count. Lab Hematol 2001, 7:89-100.

22. Bain BJ: Performing a blood count. In Blood Cells: A Practical Guide. 4 edition. Edited by: Barbara JB. Oxford: Wiley-Blackwell; 2006:20-60

23. Shapiro HM: Practical Flow Cytometry. 4 edition. Hoboken, NJ: Wiley Liss, John Wiley and Sons Inc; 2003.

24. Nishi-ku T: Analysis of samples with Plasmodium falciparum malaria in red blood cells. Sysmex Journal International 1992, 2:80-82.

25. Bunyaratvej A, Butthep P, Bunyaratvej P: Cytometric analysis of blood cells from malaria-infected patients and in vitro infected blood. Cytometry 1993, 14:81-85.

26. Kim HR, Park BR, Lee MK: Effects of bacteria and yeast on WBC counting in three automated hematology counters. Ann Hematol 2008, 87:557-562.

27. Grobusch MP, Hanscheid T, Kramer B, Neukammer J, May J, Seybold J, Kun JF, Suttorp N: Sensitivity of hemozoin detection by automated flow cytometry in non- and semi-immune malaria patients. Cytometry B Clin Cytom 2003, 55:46-51.

28. Hanscheid T, Valadas E, Grobusch MP: Automated malaria diagnosis using pigment detection. Parasitol Today 2000, 16:549-551.

29. Kramer B, Grobusch MP, Suttorp N, Neukammer J, Rinneberg H: Relative frequency of malaria pigment-carrying monocytes of nonimmune and semi-immune patients from flow cytometric depolarized side scatter. Cytometry 2001, 45:133-140.

30. Dromigny JA, Jambou R, Scott CS, Perrier-Gros-Claude JD: Performance evaluation of automated depolarization analysis for detecting clinically 
unsuspected malaria in endemic countries. Trans $R$ Soc Trop Med Hyg 2005, 99:430-439.

31. Hanscheid T, Pinto BG, Cristino JM, Grobusch MP: Malaria diagnosis with the haematology analyser Cell-Dyn 3500: What does the instrument detect? Clin Lab Haematol 2000, 22:259-261.

32. Suh IB, Kim HJ, Kim JY, Lee SW, An SS, Kim WJ, Lim CS: Evaluation of the Abbott Cell-Dyn 4000 hematology analyzer for detection and therapeutic monitoring of Plasmodium vivax in the Republic of Korea. Trop Med Int Health 2003, 8:1074-1081.

33. Rathod DA, Patel V, Kaur AA, Patel VD, Patel DD: Diagnosis of acute malaria by laser based cell counter with comparison of conventional and recent techniques in Indian scenario. Indian J Pathol Microbiol 2009, 52:185-188.

34. Hanscheid T, Langin M, Lell B, Potschke M, Oyakhirome S, Kremsner PG, Grobusch MP: Full blood count and haemozoin-containing leukocytes in children with malaria: diagnostic value and association with disease severity. Malar J 2008, 7:109.

35. Scott CS, van Zyl D, Ho E, Meyersfeld D, Ruivo L, Mendelow BV, Coetzer TL: Automated detection of malaria-associated intraleucocytic haemozoin by Cell-Dyn CD4000 depolarization analysis. Clin Lab Haematol 2003, 25:77-86.

36. Wever PC, Henskens YM, Kager PA, Dankert J, van Gool T: Detection of imported malaria with the Cell-Dyn 4000 hematology analyzer. J Clin Microbiol 2002, 40:4729-4731.

37. Fawzi ZO, Fakhro NA, Nabhan RA, Alloueche A, Scott CS: Differences in automated depolarization patterns of Plasmodium falciparum and $P$. vivax malaria infections defined by the Cell-Dyn CD4000 haematology analyser. Trans R Soc Trop Med Hyg 2003, 97:71-79.

38. Grage-Griebenow E, Flad HD, Ernst M: Heterogeneity of human peripheral blood monocyte subsets. J Leukoc Biol 2001, 69:11-20.

39. Hanscheid T, Melo-Cristino J, Pinto BG: Automated detection of malaria pigment in white blood cells for the diagnosis of malaria in Portugal. Am J Trop Med Hyg 2001, 64:290-292.

40. Josephine FP, Nissapatorn V: Malaria: the value of the automated depolarization analysis. Southeast Asian J Trop Med Public Health 2005, 36(Suppl 4):68-72.

41. Padial MM, Subirats M, Puente S, Lago M, Crespo S, Palacios G, Baquero M: Sensitivity of laser light depolarization analysis for detection of malaria in blood samples. J Med Microbiol 2005, 54:449-452.

42. de Langen AJ, van Dillen J, de Witte P, Mucheto S, Nagelkerke N, Kager P: Automated detection of malaria pigment: feasibility for malaria diagnosing in an area with seasonal malaria in northern Namibia. Trop Med Int Health 2006, 11:809-816.

43. Hanscheid T, Langin M, Codices V, Luty AJ, Adegnika AA, Kremsner PG, Grobusch MP: Automated detection of haemozoin-containing monocytes for the diagnosis of malaria in microscopically negative cases during pregnancy. Acta Trop 2009, 109:245-246.

44. Scott CS, Van Zyl D, Ho E, Ruivo L, Kunz D, Coetzer TL: Patterns of pseudoreticulocytosis in malaria: fluorescent analysis with the Cell-Dyn CD4000. Clin Lab Haematol 2002, 24:15-20.

45. Ben-Ezra J, St-Louis M, Riley R: Automated malarial detection with the Abbott Cell-Dyn 4000 hematology analyzer. Lab Hematol 2001, 7:61-64.

46. Hoffmann JJ, Pennings JM: Pseudo-reticulocytosis as a result of malaria parasites. Clin Lab Haematol 1999, 21:257-260.

47. Day NP, Pham TD, Phan TL, Dinh XS, Pham PL, Ly VC, Tran TH, Nguyen TH, Bethell DB, Nguyan HP, White NJ: Clearance kinetics of parasites and pigment-containing leukocytes in severe malaria. Blood 1996, 88:4694-4700

48. Briggs C, Da Costa A, Freeman L, Aucamp I, Ngubeni B, Machin SJ: Development of an automated malaria discriminant factor using VCS technology. Am J Clin Pathol 2006, 126:691-698.

49. Fourcade C, Casbas MJ, Belaouni H, Gonzalez JJ, Garcia PJ, Pepio MA: Automated detection of malaria by means of the haematology analyser Coulter GEN.S. Clin Lab Haematol 2004, 26:367-372.

50. Ruzicka K, Veitl M, Thalhammer-Scherrer R, Schwarzinger I: The new hematology analyzer Sysmex XE-2100: performance evaluation of a novel white blood cell differential technology. Arch Pathol Lab Med 2001, 125:391-396.

51. Campuzano-Zuluaga G, Alvarez-Sanchez G, Escobar-Gallo GE, ValenciaZuluaga LM, Rios-Orrego AM, Pabon-Vidal A, Miranda-Arboleda AF, BlairTrujillo S, Campuzano-Maya G: Design of malaria diagnostic criteria for the Sysmex XE-2100 hematology analyzer. Am J Trop Med Hyg 2010, 82:402-411.

52. Huh J, Jung J, Yoon H, Chung W: Pseudoeosinophilia associated with malaria infection determined in the Sysmex XE-2100 hematology analyzer. Ann Hematol 2005, 84:400-402.

53. Park GB, Cha YJ: [Three cases of pseudoeosinophilia associated with malaria determined in the Sysmex XE-2100 automated hematology analyzer]. Korean J Lab Med 2006, 26:77-80.

54. Huh HJ, Oh GY, Huh JW, Chae SL: Malaria detection with the Sysmex XE2100 hematology analyzer using pseudoeosinophilia and abnormal WBC scattergram. Ann Hematol 2008, 87:755-759.

55. Yoo JH, Song J, Lee KA, Sun YK, Kim YA, Park TS, Choi JR: Automated detection of malaria-associated pseudoeosinophilia and abnormal WBC scattergram by the Sysmex XE-2100 hematology analyzer: a clinical study with 1,801 patients and real-time quantitative PCR analysis in vivax malaria-endemic area. Am J Trop Med Hyg 2010, 82:412-414.

56. Yan F, Dai Y, Zhang Z, Wan H: The correlation of abnormal information in Sysmex hematology analyzers XE-2100 and XS-1000i with diagnosis of plasmodium infection. Sysmex Journal International 2008, 18:50-53.

57. WHO: The role of laboratory diagnosis to support malaria disease management. Book The role of laboratory diagnosis to support malaria disease management (Editor ed.^eds.) City 2006, 5-6.

58. Hanscheid T, Pinto BG, Pereira I, Cristino JM, Valadas E: Avoiding misdiagnosis of malaria: a novel automated method allows specific diagnosis, even in the absence of clinical suspicion. Emerg Infect Dis 1999, 5:836-838

59. Brown GV, Battye FL, Howard RJ: Separation of stages of Plasmodium falciparum-infected cells by means of a fluorescence-activated cell sorter. Am J Trop Med Hyg 1980, 29:1147-1149.

60. Saito-Ito A, Akai Y, He S, Kimura M, Kawabata M: A rapid, simple and sensitive flow cytometric system for detection of Plasmodium falciparum. Parasitol Int 2001, 50:249-257.

61. van Vianen $\mathrm{PH}$, van Engen $\mathrm{A}$, Thaithong $\mathrm{S}$, van der Keur $\mathrm{M}$, Tanke $\mathrm{HJ}$, van der Kaay HJ, Mons B, Janse CJ: Flow cytometric screening of blood samples for malaria parasites. Cytometry 1993, 14:276-280.

62. Leke RF, Djokam RR, Mbu R, Leke RJ, Fogako J, Megnekou R, Metenou S, Sama G, Zhou Y, Cadigan T, et al: Detection of the Plasmodium falciparum antigen histidine-rich protein 2 in blood of pregnant women: implications for diagnosing placental malaria. J Clin Microbiol 1999, 37:2992-2996.

63. Lyke KE, Diallo DA, Dicko A, Kone A, Coulibaly D, Guindo A, Cissoko Y, Sangare L, Coulibaly S, Dakouo B, et al: Association of intraleukocytic Plasmodium falciparum malaria pigment with disease severity, clinical manifestations, and prognosis in severe malaria. Am J Trop Med Hyg 2003, 69:253-259.

64. Kremsner PG, Valim C, Missinou MA, Olola C, Krishna S, Issifou S, Kombila M, Bwanaisa L, Mithwani S, Newton CR, et al: Prognostic value of circulating pigmented cells in African children with malaria. J Infect Dis 2009, 199:142-150

65. Hanscheid T, Frita R, Langin M, Kremsner PG, Grobusch MP: Is flow cytometry better in counting malaria pigment-containing leukocytes compared to microscopy? Malar J 2009, 8:255.

66. Kang YH, Lim HS, Lee HM, Lee KS, Choi KM: [Evaluation of usefulness of the panel test composed of malaria non-specific tests as a surrogate marker]. Korean J Lab Med 2008, 28:332-338.

doi:10.1186/1475-2875-9-346

Cite this article as: Campuzano-Zuluaga et al: Automated haematology analysis to diagnose malaria. Malaria Journal 2010 9:346. 